\title{
TAHSP:-
}

The Internet Joưnal of Allied Health Sciences and Practice

A Peer Reviewed Publication of the College of Health Care Sciences at Nova Southeastern University

Dedicated to allied health professional practice and education

http://ijahsp.nova.edu Vol. 12 No. 4 ISSN 1540-580X

\section{Impact of Various Collegiate Settings on Athletic Trainers' Definition of Professional Commitment}

\author{
Stephine Mazerolle, PhD, ATC 1 \\ Christianne M. Eason, MS, ATC2
}

1. Assistant Professor, Entry-Level Athletic Training Education Department of Kinesiology, University of Connecticut, Storrs, Connecticut

2. Doctoral Candidate, Department of Kinesiology, University of Connecticut, Storrs, Connecticut

United States of America

CITATION: Mazerolle S, Eason C. Impact of Various Collegiate Settings on Athletic Trainers' Definition of Professional Commitment. The Internet Journal of Allied Health Sciences and Practice. Oct 2014. Volume 12 Number 4.

\section{ABSTRACT}

Purpose: Professional commitment is an individualized concept that combines commitment to a profession and the organization of employment. Currently there is no distinct definition of professional commitment within the context of athletic training. Therefore, the purpose of our study was to evaluate the impact of collegiate divisional setting on the definition of professional commitment. Methods: Online asynchronous interviews. Inclusion criteria consisted of full-time employment in the collegiate setting with at least 1 year of experience beyond a graduate assistantship. Thirty-three BOC certified ATs employed in the collegiate setting (Division I $=11$, Division II $=9$, Division III $=13$ ) volunteered with an average of $10 \pm 8$ years of clinical experience. Data saturation guided the total number of participants. Participants journaled their thoughts and experiences via QuestionPro ${ }^{\mathrm{TM}}$. Multiple analyst triangulation and peer review were included and data was analyzed utilizing general inductive analysis. Results: The importance of current practices emerged across all three settings. ATs in the Division I setting viewed commitment as advocating for their student athletes, providing the best care possible, and mentoring them as young adults. In the Division II setting, ATs were focused on life-long learning as a reflection of commitment. This was often accomplished by attending seminars, completing CEUs, and continually adding to their skill set in order to provide the best care for their student athletes. Division III focused their definition on being a multifaceted health care provider. Exceeding expectations and being a dedicated professional was an aspect of professional commitment. Conclusions: It is important to understand what keeps ATs motivated in the profession in order to enhance retention strategies. Overall, ATs' professional commitment is derived from providing quality care to student-athletes, continuously advancing education within the profession, and being a multifaceted healthcare provider.

\section{INTRODUCTION}

A profession is often labeled as a paid occupation, one which requires formal training over a period of time.1 To become a professional, one essentially must invest time, energy, and money to learn and practice the skills required to become successful in that professional role. In athletic training, an athletic training recruit must complete an accredited degree program, gain certification through the Board of Certification, and then in many cases, complete a graduate degree to gain additional training and develop confidence in their skills. Theoretically, once completing all these necessary requirements, the athletic trainer should demonstrate commitment to the profession and their future role as a health care provider. Longevity, however, has been questioned within the field of athletic training, indicating professional commitment could be impacted. Several constructs have 
been blamed including work-family conflict, burnout and job satisfaction.2-6 Limited understanding, however, exists regarding professional commitment in athletic training.

Professional commitment is commonly designated by the strength of an individual's identification with and involvement in a profession.7 Professional commitment should not be confused with organizational commitment. Although parallel constructs, organizational commitment is specific to the one's place of current employment, whereas professional commitment is more global representing the profession itself. Career and occupational commitment are other terms that are often interchanged for professional commitment, but defined comparably.8-10 Regardless, the underpinnings are the same and reflect an individual's loyalty and obligation to their profession. Professional commitment also reflects a positive or negative attitude towards one's profession and may be impacted by many different tenants including modifiable variables such as age, gender, and years of experience, as well as educational training including opportunities to become integrated, previous experiences, and finally workplace characteristics containing engaging and collegial relationships.11-13

Professional commitment has emerged as a leading focus for scholars, as the connection has been made between a professional's level of commitment and retention within their field.9-11 Unequivocally, an individual who expresses commitment for the field they are employed in are more likely to remain steadfast as well as exhibit higher outcome performances.7,14 In athletic training, professional performance is predicated on delivery of patient care and patient outcomes. Professional commitment has implications on retention within the field, as previous literature has suggested factors such as job satisfaction, work-life balance, and burnout can negatively impact an athletic trainer's perceptions of longevity and lead to departure.2,15 Furthermore, literature suggests that job satisfaction, work-life balance, burnout, and professional commitment are directly influenced by one another, yet are distinctive constructs. 16 These professional issues share an underlying, fundamental concept, which relates to the individuality of each, whereby a person's values, beliefs, and experiences influence the perceptions of the concept. However, each concept measures different aspects of an individual's life and experiences in the workplace.

Although Winterstein and Pitney have examined the concept of professional commitment within college athletics and beyond, one limitation was a failure to evaluate how the individual defines the concept personally.8,17 Determining this delineation as viewed by the athletic trainer can help provide substance to the findings of literature evaluating factors negatively and positively impacting an athletic trainer's assessment of professional commitment. The purpose of this study was to contextualize the term professional commitment for those athletic trainers who are employed in the intercollegiate setting and to determine if any differences exist regarding the definition of professional commitment based on NCAA Division setting. To fully appreciate data regarding professional commitment in athletic training, it is necessary to understand what facets are viewed as framing it for the athletic trainer. Simply, professional commitment is an individual's assessment of how strongly they associate with their profession and its values and attitudes. The construct in of itself is personal, thus warranting the need to appreciate its meaning to the athletic trainer. The intercollegiate setting itself has been of central focus on constructs such as work-life balance, retention, to the athletic trainer. The intercollegiate setting itself has been of central focus on constructs such as work-life balance, retention, job satisfaction, and burnout; predominantly as it is one of the largest employment settings for the athletic trainer6 and is described as time intensive and demanding; something that may influence the athletic trainer's perceptions of the concept.6,18

\section{METHODS}

\section{Theoretical Framework}

The underlying thread of professional commitment is the psychological component to the construct. Vandenberg and Scarpello's extensively used definition highlights professional commitment as a person's belief in their selected occupation and desire to remain a member within the occupation.19 Meyer et al proposed that professional commitment extends beyond the simplicity of the previous definition and developed a three-component model to describe an individual's development of an attachment to their profession.10 The model encompasses affective, normative, and continuance commitment. Affective professional commitment reflects the emotional attachment a person develops with their profession, thus the more positive the experiences the more likely they are to be vested by attending professional meetings and conferences. Normative professional commitment is described as perceived obligation towards a profession and commitment results because of their sense of duty and identification with the professional role. Continuance professional commitment reflects an individual's assessment of the cost of remaining in the profession versus leaving. This type of commitment reflects both social and economic costs related to continuing in the profession. Combined, all three components have inferences on whether an individual decides to stay or leave their profession.20 Intent to stay in the profession, a degree of professional commitment, has direct and indirect ties with already documented outcomes in athletic training such as burnout, work-life imbalance, and job dissatisfaction; thus an important concept for investigation.

(c) The Internet Journal of Allied Health Sciences and Practice, 2014 


\section{Research Design}

The construct, professional commitment, is rooted in the perception of the person, whereby they are assessing their experiences within the profession on an individual basis. As described by the Meyer and Allen model, professional/organizational commitment is an emotional link between an employee and his or her chosen field. ${ }^{9}$ As such, a purely exploratory qualitative research study provides the backbone for data collection to allow us to fully capture the athletic trainer's definition of professional commitment. Denzin suggests the paradigm allows the researchers to better understand "phenomena in terms of the meanings people bring to them," like the development of professional commitment.21,22

\section{Recruitment and Participant Sampling}

Sampling was purposeful and data saturation guided recruitment of participants. ${ }^{23} \mathrm{~A}$ list was developed of 15 athletic trainers within each of the three Divisions. The list was reflective of professional networks of the authors, but incorporated those athletic trainers with at least one year of experience and a full-time position as an athletic trainer in the college setting. All potential athletic trainers were contacted via email, once IRB approval from the University of Connecticut was gained, and indicated consent by completing the online, structured interview guide.

In total, thirty-three athletic trainers (Division I $=11$, Division $I I=9$, Division III $=13$ ) volunteered for our study. All were full-time and certified through the Board of Certification with an average $10 \pm 8$ years of clinical experience. Participants represented eight different NATA districts. The highest degree obtained by 29 of the 33 participants was a Master's Degree. Of our 33 participants, $16(48 \%)$ have experience working only in their current NCAA Division. Years of experience in current NCAA Division ranged from 1 to 32 years, with the average years of experience in currently employed NCAA Division being 8 years +8.5 . Table 1 displays individual participant demographic information. All participants are referred to by pseudonyms throughout the context of this paper.

\begin{tabular}{|c|c|c|c|c|c|c|c|}
\hline Pseudnym & Sex & NATA District & $\begin{array}{l}\text { Current } \\
\text { Position }\end{array}$ & $\begin{array}{l}\text { NCAA } \\
\text { Division }\end{array}$ & $\begin{array}{l}\text { Yrs Exp in } \\
\text { Current Div }\end{array}$ & Yrs Certified & $\begin{array}{l}\text { Highest } \\
\text { Education }\end{array}$ \\
\hline Angela & $\mathrm{F}$ & 2 & Asst AT & 1 & 4 & 4 & MS \\
\hline Bailey & $F$ & 4 & Asst AT & 1 & 6 & 6 & MS \\
\hline Cameron & $M$ & 10 & Asst AT & 1 & 5 & 5 & MS \\
\hline Chris & $M$ & 9 & Asst AT & 1 & $8^{*}$ & 12 & MS \\
\hline Corey & $M$ & 2 & Assoc AT & 1 & 10 & 10 & MS \\
\hline Kristen & $\mathbf{F}$ & 1 & Asst AT & 1 & 7 & 7 & MS \\
\hline Meg & $F$ & 4 & DoSM & 1 & 25 & 25 & PhD \\
\hline Nina & $\mathrm{F}$ & 2 & Asst AT & 1 & $5^{*}$ & 8 & MS \\
\hline Sean & $M$ & 9 & Assoc AT & 1 & $3^{*}$ & 9 & MS \\
\hline Seth & $M$ & 3 & Head AT & 1 & $17^{*}$ & 19 & MS \\
\hline Whitney & $\mathrm{F}$ & 3 & Asst AT & 1 & $2^{*}$ & 4 & MS \\
\hline Devon & $M$ & 7 & Asst AT & 2 & 1 & 1 & BS \\
\hline Hannah & $F$ & 7 & Head AT & 2 & 7 & 7 & MS \\
\hline Jenn & $\mathbf{F}$ & 6 & Asst AT & 2 & $5^{*}$ & 7 & MS \\
\hline Jonah & $M$ & 9 & Asst AT & 2 & $3^{*}$ & 6 & MS \\
\hline Martin & $M$ & 1 & Head AT & 2 & $30^{*}$ & 32 & MS \\
\hline Paloma & $\mathrm{F}$ & 2 & Head AT & 2 & $5^{*}$ & 7 & MS \\
\hline Scott & $M$ & 9 & Head AT & 2 & $11^{*}$ & 15 & MS \\
\hline Shana & $F$ & 9 & Asst AT & 2 & 2 & 2 & MS \\
\hline Wendy & $\mathrm{F}$ & 3 & Head AT & 2 & 7 & 7 & MS \\
\hline Aidan & $M$ & 1 & Asst AT & 3 & $1^{*}$ & 3 & MS \\
\hline Alisha & $F$ & 1 & Head AT & 3 & $2^{*}$ & 5 & MS \\
\hline Annie & $\mathrm{F}$ & 1 & Asst AT & 3 & $4^{*}$ & 6 & MS \\
\hline Ari & $M$ & 1 & Asst AT & 3 & $1^{*}$ & 3 & MS \\
\hline Brandon & $M$ & 1 & Head AT & 3 & 6 & 6 & MS \\
\hline Ian & $M$ & 1 & Asst AT & 3 & $2^{*}$ & 4 & BS \\
\hline Kaleb & $M$ & 1 & Head AT & 3 & 10 & 10 & MS \\
\hline Maison & $M$ & 1 & Asst AT & 3 & $2^{*}$ & 4 & MS \\
\hline Myra & $F$ & 1 & Asst AT & 3 & 8 & 8 & MS \\
\hline Nick & $M$ & 9 & Asst AT & 3 & 7 & 7 & MS \\
\hline Ralph & $M$ & 1 & Head AT & 3 & 30 & 30 & MS \\
\hline Richard & $M$ & 1 & Head AT & 3 & 32 & 32 & BS \\
\hline Zach & $M$ & 3 & DoSM & 3 & $5^{*}$ & 7 & MS \\
\hline
\end{tabular}




\section{Instrument}

The structured interview guide (Appendix A) was developed for this study using a combination of open and close-ended questions. The questions were derived and borrowed from the existing literature, including the recent investigation by Pitney within the secondary school setting..$^{17}$ Questions were adapted to fit the occupational setting as well as the additional literature since the publication of the Pitney study. We conducted a peer review and small pilot study prior to data collection to primarily ensure content and face validity of the instrument.

The peer review provided us with a content analysis, ensuring we captured an accurate, realistic, and appropriate interview guide to help us answer our intended research purpose. The peer brought knowledge in the area of professional commitment, social behaviors and attitudes, and qualitative inquiry. With over 15 years of experience as a qualitative scholar and editorial experience, the peer was able to establish a reliable instrument for data collection. The review revealed the addition of several questions as well as grammatical edits. Upon completion of the peer review, the instrument was piloted. The pilot revealed no issues confirming the peer's review of the instrument and was completed by two athletic trainers fitting our recruitment criteria.

\section{Data Collection}

Data was collected using QuestionPro ${ }^{\mathrm{TM}}$. Online journaling provides a suitable medium to collect participant's experiences and thoughts regarding professional commitment. Asynchronous interviewing, unlike the traditional methods of interviewing, provides the chance for contemplation and a more deliberate answer, which allows for more rich, descriptive data. ${ }^{24}$ Participants, when presented with a question online, have the chance to respond to the question at their leisure, which often affords time for greater reflection and time to structure their thoughts through journaling, likely leading to greater disclosure and detail. The lack of personal contact by using asynchronous interviewing can be viewed as a disadvantage; however, as there is an increase in the use of social media and technology as a means to communicate, we believe online interviewing is beneficial-particularly when evaluating the advantages including access to a regionally diverse group of participants, reducing issues with scheduling interviews, and diminishing the inconvenience placed upon the participant with time demands. ${ }^{24}$

Data collection took place during in the spring of 2013. Each participant was sent an individual email inviting them to participate by completing an online questionnaire regarding the topic of professional commitment. The initial email was sent with the invitation and the link to the questionnaire. Two-weeks after the initial email, a reminder was sent to each participant to encourage participation. A final reminder was sent one week after the first reminder. This first round of recruitment was enough to help reach data saturation, as analysis as described next, was on-going throughout the data collection period.

\section{Data Analysis}

We used an inductive content analysis with the textual data following procedures outlined by Pitney and Parker. ${ }^{23}$ We selected this analysis procedure to allow for a systematic method to evaluate the textual data as a way to provide rigor and objectivity when analyzing large amounts of data. Inductive analysis can be helpful when trying to uncover patterns in the data as it relates to a specific research question. ${ }^{23}$ We present an example of our coding schematic in Table 2. Our analysis process was strategic, and questions from the instrument that were focused on defining professional commitment were targeted for this manuscript. Evaluation of factors influencing professional commitment were assessed, but presented in two separate manuscripts. ${ }^{25,26}$ Prior to analysis, we determined coded concepts needed to be produced by $50 \%$ of all participants to be included in the final presentation of the results. These procedures are consistent with other published qualitative studies in athletic training, but specifically as related with professional commitment. ${ }^{17}$ During the initial coding process, an open coding method was utilized, which allowed us to craft notes and headings in the transcripts. After all transcripts were read, similar headings and codes were grouped together and labeled to reflect the global meaning of each.

\section{Table 2. Example of Coding Schematic}

\begin{tabular}{|c|c|c|}
\hline Response & Initial Code & Focused Code \\
\hline $\begin{array}{l}\text { "I feel I have an obligation to be current on research and clinical } \\
\text { practices working at a university." }\end{array}$ & Research/Clinical Practice & \multirow[b]{2}{*}{ Current Practices } \\
\hline $\begin{array}{l}\text { "Staying current with research and applying it to my daily work, } \\
\text { when applicable." }\end{array}$ & Apply research & \\
\hline Response & Initial Code & Focused Code \\
\hline $\begin{array}{l}\text { "We provide encouragement, strength, and many times tissues to } \\
\text { help build our athletes, patients, clients into strong people." }\end{array}$ & Supportive relationships & \multirow[b]{2}{*}{$\begin{array}{l}\text { Interactions with } \\
\text { Student Athletes }\end{array}$} \\
\hline $\begin{array}{l}\text { "Being somebody who they can rely on and who they turn to for all } \\
\text { those things as well as the big things. Support and guidance. } \\
\text { Making their experiences all it can be. }\end{array}$ & Guidance and mentoring & \\
\hline
\end{tabular}

(c) The Internet Journal of Allied Health Sciences and Practice, 2014 
Initially, participant responses ere separated based on demographic employment setting (ie Division I, Division II, or Division III) in order to determine professional commitment definitions of employees within each setting. In the results, the findings are presented based on this demographic separation. After analyzing the Divisions separately, the textual data were combined to look for commonalities among the Divisions in an attempt to gain a holistic sense of the overall data. The commonalities observed between Divisions will be discussed in the discussion section.

Trustworthiness was established using two tactics. First, multiple analyst triangulation was completed with one researcher following the previously outlined procedures. Separately, three undergraduate students who were instructed by the previous researcher on the content analysis coding technique also completed the review of the textual data. The students were instructed on using the research agenda to guide their analysis and labeling. A second researcher with experience in qualitative methodology completed a separate review of the data. Researchers identified their own personal beliefs and experiences regarding professional commitment and articulated them in writing to identify if biases entered into data analysis. It was important to identify our own beliefs to ensure we were not interpreting results in a prejudiced manner. Once identified, it became clear if these biases entered into the analysis of data. Upon completion of the review independently by the students and both researchers, emergent themes were generated and then negotiated. During the meeting these researchers deliberated the meaning of the codes to one another and how they populated the various themes and negotiated the ultimate construction of each theme. Content was the same and the negotiations were focused on providing the best label for the theme. For example, textual data referring to "providing care" and "treatment" was labeled as "providing the best medical care possible." A peer reviewer examined the transcripts and coding sheets to verify the findings and ascertain data credibility. Our peer has been trained in qualitative research methods through her doctoral studies and has experience in publishing in qualitative methodologies.

\section{RESULTS}

As the results were analyzed separately based on employment setting, the themes that were found for each Division setting will be presented independently. The analysis revealed three emergent themes for the Division I setting, two themes within the Division II setting, and three themes within the Division III setting. There was some noticeable overlap among the Divisions, and this will be discussed in the discussion. Each theme is presented below with supporting textual data.

\section{Division I Clinical Setting}

Three major factors emerged defining professional commitment for the athletic trainer at the Division I setting, including current practices, interactions with the student-athlete, and role as medical care provider.

\section{Current Practices}

As described by our participants, professional commitment was linked to maintaining medical current practices "to continue learning and growing as a clinician." One of our Division I athletic trainers stated, "I feel I have an obligation to be current on research and clinical practices working at a university." Professional commitment as described by our participants required a conscious effort to be current, to seek "continuing education to better fill in the gaps of my current education," and to develop skills beyond their initial education. Nina told us that professional commitment means "...to stay current with skills [and] research in order to provide the best care possible for my student athletes." Other participants across the three levels used terms such as being "current" and "understanding best practices" were also mentioned as factors related to professional commitment.

\section{Interactions with the Student-Athlete}

Eight of the 11 athletic trainers employed within the NCAA Division I setting discussed professional commitment as something that embodied the quality of the interactions with the student-athletes. A Director of Sports Medicine who has been certified as an athletic trainer for 25 years revealed, "The interaction with the student-athletes, making their college athletic experience good, making them feel safe and cared for when they are injured and unable to participate [keeps me committed]." An assistant athletic trainer described his/her professional commitment as something that encompasses "seeing that growth and how it can help them succeed on and off the field." The idea of student-athlete success was also highlighted by Kristen, who shared, "When you get an athlete back to playing after a long period of time, or a difficult road, and you see them compete and do what makes them happy, that is the best part of my job. To give them the tools necessary to be successful drives me to get to that outcome."

In addition to the day-to-day interactions, mentoring also materialized as a component of professional commitment, whereby the relationships developed between the student-athlete and the athletic trainer stimulate commitment. Mentorship is a hierarchical relationship and is often described as a more experienced individual guiding a less experienced one to help them succeed. Mentorship is often described as support and encouragement provided to a person simply to help them reach their maximum potential. Angela is able to demonstrate her mentoring role through her comments regarding the meaning of professional

(c) The Internet Journal of Allied Health Sciences and Practice, 2014 
commitment; "We provide encouragement, strength, and many times, tissues to help build our athletes, patients, clients into strong people." 25 year certified athletic trainer Meg contextualized professional commitment as

"The student-athletes. It is how we affect and impact them. Being there for them when they need us physically, mentally, and emotionally. Being somebody who they can rely on and who they turn to for all those things as well as the big things. Making their experiences all it can be."

The mentoring relationship positively impacts not only the student-athlete but provides reciprocal benefits for the athletic trainer. As Bailey stated, "When they [student-athletes] come in to work with me they typically have a drive to work hard and get better. When you work this closely with athletes you build a strong relationship with them and enjoy seeing them succeed."

Commitment incorporated a strong attachment to the needs of the student-athletes, and the previously presented quotes speak to the relationships developed and supporting the student-athlete's healthy participation in athletics.

\section{Role as Medical Care Provider.}

Professional commitment was summarized as one that involves the athletic trainer serving as a medical care provider. Specifically, as it pertains to providing the student-athlete with the best medical care possible. Eight of the 11 athletic trainers employed at the Division I setting described professional commitment as incorporating the best level of care to their studentathletes. For example, Cameron, a certified assistant athletic trainer with 5 years of clinical experience said professional commitment is "personal responsibility and commitment to my job by providing a high level of care [to my student-athletes]." Angela, another Division I athletic trainer, despite battling challenging and demanding days said this about professional commitment, "there are days that are difficult to come to work, but I strive [every day] to keep my personal life out of my work and provide the best care possible to all of those I am responsible for [on a regular basis]." Additionally, an associate athletic trainer with 9 years of clinical experience reiterated this by stating that professional commitment means "overseeing the healthcare of all of the student-athletes at the institution I am employed."

The rehabilitation process athletic trainers share with their athletes was another facet of being a health care provider and providing the best medical care possible that our participants used to describe their professional commitment. As Corey, an associate athletic trainer with 10 years of experience stated when asked what aspects of the profession he has a passion for, "[The] majority of my passion is during the rehabilitation phase of athletic training." This is echoed by Whitney who described the phase professional commitment as, "Creating rehab programs for athletes..." Angela reflected on her four years of certification as an athletic trainer and expanded on this idea by stating, "in order to sustain professional enthusiasm, I try to keep my rehab and treatments very tailored to the individual I am working with. It keeps it more interesting for the athlete and [me]."

\section{Division II Clinical Setting}

Two major themes emerged to contextualize how Division II athletic trainers define professional commitment, current practices and interaction with student-athletes.

\section{Current Practices}

Seven of the Nine Division II athletic trainers conceptualized professional commitment as something that incudes being passionate and seeking learning opportunities. Engaging in learning opportunities, formal and informal, was an underpinning of this emergent theme, as described by a head athletic trainer who has been certified as an athletic trainer 32 years, "continued post-masters education, continuing education seminars, and study. The more I learn the more I enjoy what I do." Shana, an assistant athletic trainer, embedded the concept of life-long learning in her definition of professional commitment, saying, "the steps that are taken by an individual in order to continue to uphold a respectful amount of professionalism whether it be through CEUs or leadership skills, etc." Commitment to a profession was further articulated by Jenn as "Presenting yourself as a person that is dedicated to continuing education, the advancement of our field as a whole, and to developing a greater understanding of what the athletic training profession does among other health care providers and lay people." Professional commitment was viewed as an obligation to developing and growing as a practitioner through continuing education. Life-long learning, unlike the current practices theme, reflects our participants' desire to seek out learning opportunities and recognizing the importance of learning more about your profession as a means to remain committed. Current practices was reflective of the dynamic nature of medicine, rather than overall commitment to learning.

\section{Interaction with Student-Athletes}

Five of the nine athletic trainers made reference to the basic role the athletic trainer serves, which includes service to the student-athlete. Simply stated, Allen shared, "providing the best care to our athletes with the resources at our disposal." Hannah, 
when asked about professional commitment, merely stated "it is reminding myself constantly that the health and wellness of my athletes is the number 1 priority." She also illustrated the importance of the athletic trainer regarding providing medical care to the student-athlete. Hannah shared, "Being an athletic trainer is not about You! It is about serving others to the best of your abilities and recognizing the incredible honor that we as athletic trainers have to be able to work with athletes in that capacity." Professional commitment includes providing a service to the student-athlete, and for the Division II athletic trainer, it is apparent that providing best care is essential.

\section{Division III Clinical Setting}

Three major themes materialized from the data to describe how the Division III athletic trainer perceived professional commitment: current practices, interactions with student athletes, and exceeding expectations.

\section{Current Practices}

This notion of current practices seems to reflect the need of the Division III athletic trainers to be as up-to-date regarding their existing knowledge and skills and also informed about new or emerging practices. For Division III collegiate athletic trainers, current practices were a central focus on staying modern with their clinical skills, mostly related to evidence-based practice. This was expressed by Aidan stated who stated, "[Professional commitment means] staying current on the literature pertaining to the field and striving to apply the current knowledge base to the tasks that are required of you." Aidan also shared that professional commitment means "staying current with research and applying it to my daily work, when applicable." Kaleb reiterates this by saying, "I keep abreast of current and new athletic training information."

\section{Interaction with Student Athletes}

Our Division III athletic trainers described commitment to the profession in terms of their dedication to their student athletes. When asked how he defined professional commitment, Brandon responded, "[Professional commitment means] sometimes going beyond your normal duties for student athletes in their time of need." He went on to say that "It means taking care of student athletes whether it be on the field or in the classroom. I develop strong bonds with the athletes and [l] want to see them succeed on the field and in life."

Nick conceptualized professional commitment as "being professional and courteous to all athletes, giving the highest level of commitment to the health and well-being of all athletes under our care." Comparably, Brandon, a head athletic trainer, said professional commitment is "being dedicated to your team..." Aidan expanded on this notion when he said:

[Professional commitment means] ensuring that the athletes have the best experience possible throughout their injury recovery and have the safest and quickest return to participation. This means attending physician's appointments with them, setting up appointment times outside of regular hours in order to fit their class and practice schedules, etc. It also means staying current with the research and applying it to my daily work, when applicable.

\section{Exceeding Expectations}

Going beyond the duties of the athletic trainer was also discussed by the Division III participants in their definitions of professional commitment. In fact, nine of the 14 shared comments regarding going beyond their normal duties as it relates to athletic training. Jenn who described professional commitment as "being dedicated...," also felt professional commitment was "going beyond your normal duties for the student-athletes, especially in their time of need." Professional commitment, as illustrated by Jenn, incorporated the idea of advancing the profession and striving to do more than previous mentors or supervisors. Ralph, a head athletic trainer for more than 30 years, said professional commitment to me is "following the tenets as set forth by predecessors and peers. Continually put forth effort to expand tenants to improve the profession so ones to follow are better than you [were]." As several others discussed going beyond the normal duties, Myra, with eight years of certification as an athletic trainer said professional commitment is "the amount of time, training, and financial investment [you make] in and out of the athletic training room that you commit to your job as an athletic trainer." Being a steadfast professional was also discussed as demonstrating professional commitment, as highlighted by Madison, a four year certified athletic trainer. They shared that professional commitment is "adhering to the responsibilities and demands of the job title no matter how large, small, inconvenient, or significant."

\section{DISCUSSION}

Professional commitment has become a central focus within the organizational behavior literature, mostly due to its impact on employee productivity, retention, and performance. ${ }^{9,27}$ The underlying determinant of professional commitment is an individual's development of a psychological bond with the profession they've selected and the strength of this connection can stimulate

(C) The Internet Journal of Allied Health Sciences and Practice, 2014 
improved satisfaction within the workplace, a direct facilitator of retention. Thus this attachment, developed by an employee, is necessary to understand as it may help improve job satisfaction, reduce potential role strain and burnout, and help retain professionals within their chosen profession.

Until recently, professional commitment within the profession of athletic training was understudied. Despite the work of Pitney, who examined the professional commitment of secondary school athletic trainers, there is a limited understanding of the development of professional commitment for the athletic trainer. ${ }^{17}$ The demanding nature of patient care coupled with the intensity of intercollegiate athletics has the potential to influence the athletic trainer's professional role and their attachment to their profession. Winterstein and Pitney, both were able to identify elements of professional commitment within the profession; however, one constraint was the failure to uncover how the athletic trainer defines professional commitment. 8,17 Our findings are able to uniquely contribute to the literature by providing context to the definition of professional commitment as perceived by the athletic trainer. It is essential for the profession to determine the athletic trainer's definition of professional commitment to better recognize potential organizational conflicts that may arise, such as staffing issues or support for continuing education. Retaining experienced and professionally committed athletic trainers will benefit the athletic organization, as they will deliver quality patient care to their student-athletes. Our findings suggest that athletic trainers visualize professional commitment as a notion that encompasses affection for and a sense of obligation towards their professional role as a health care provider. As such, our findings suggest that an athletic trainer's professional commitment can be linked to two of the three elements within the commitment model as developed by Meyer and Allen. ${ }^{9}$ Simply, athletic trainers show affective and normative commitment, whereby they have a positive emotional attachment through their relationships with their student-athletes as well as an obligation to provide the best possible patient care.

We found that regardless of divisional setting, athletic trainers at the collegiate level define professional commitment as maintaining current levels of practice and a dedication to the student athletes that they work with. This is important to highlight, as it shows that regardless of employment setting, collegiate athletic trainers have a commonality in their definition of professional commitment. Additionally we found that Division I, athletic trainers incorporated their role as a medical care provider into their definition of professional commitment, and Division III athletic trainers incorporated exceeding expectations into their definition. Perhaps athletic trainers in the Division III setting, who often work within smaller budgets and with fewer athletic trainers on staff, feel as though their commitment to their student athletes enables them to work well within their limits and to utilize their resources to the best of their abilities. In contrast, athletic trainers employed within the Division I setting who typically have fewer financial constraints and often more current medical equipment and supplies can focus more on their role as a health care provider. They may not be as concerned as their Division III counterparts with exceeding expectations because they feel as though the environment they work in has very high standards. They do not attempt to exceed expectations; rather, they focus on providing the best care possible to their student-athletes. Future examination of these differences would be warranted, as we cannot say for sure what may have prompted our participants to answer in the manner they did.

Our findings yield support to the early work of Winterstein and Pitney and the recent work of Pitney and Eason et al, who identify that affective (emotional attachment a person develops to their profession) and normative (individual's perceived obligations toward a profession) dimensions of professional commitment as described by Meyer and Allen resonate with athletic trainers. $8,9,17,26$ Pitney found that the driving stimulus for the secondary school athletic trainer was professional responsibility to their student-athletes and ensuring they received appropriate, timely, and the best possible care. Correspondingly, Winterstein reported head athletic trainers demonstrated strong attachment and responsibility to their student-athletes and the relationships and rapport they develop with them over time.$^{8}$ Affective commitment materializes because the athletic trainer gains satisfaction from their role, and as found previously, athletic trainers are attracted to the career because of the chance to be a part of a team, interest in the medical field, and the love of sport, essentially creating a satisfying experience. .12 This idea of intrinsic rewards being gained from interactions with students athletics was brought up by both Eason et al and Pitney. Moreover, satisfaction with one's role and work environment has been found to stimulate retention for athletic trainers, a factor related to professional commitment. ${ }^{17,26,29}$ Like affective commitment, normative commitment matures because of satisfying experiences, and a sense of duty to one's patients as described by our participants as well as those included in the Pitney examination. ${ }^{17}$ Our participants discussed their duty to their student-athletes, which was a central focus of their contextualization of professional commitment--a founding component of affective commitment as defined by Meyer and Allen's commitment. ${ }^{9}$ Having a mental connection to clinical practice and patient care, has also been described within the medical literature as a facet of professional commitment. ${ }^{30}$

Literature that has previously explored differences between the levels within the collegiate setting have often found very little differences, particularly in experiences of job satisfaction, intentions to leave, and work-life balance. ${ }^{31-33}$ We found two main threads in the definition of professional commitment, interaction with student athletes and current practices. . These results speak to the concept of professional responsibility-a primary facilitator and component of professional commitment for the

(c) The Internet Journal of Allied Health Sciences and Practice, 2014 
athletic trainer. Interestingly, this idea of life-long learning or chances for continuing education has not been linked to improved professional commitment for nurses, where opportunities to engage in professional development was not deemed as critical for professional commitment as other facets such as time off and family-friendly workplace practices. ${ }^{34}$ The nature of the athletic trainer's role is often considered multi-faceted, including patient-care, collaborating with other healthcare providers, communicating with members of the sports medicine team, and administrative paperwork. Our participants indicated that professional commitment encompassed being able to provide and meet the needs of the student-athlete, again illustrating the connection to an affective and normative commitment. ${ }^{9}$

\section{LIMITATIONS, PRACTICAL IMPLICATIONS, FUTURE DIRECTION}

We recognize that our findings can only be applied to the collegiate setting, as we only sampled from those who were currently employed in NCAA Division I, II, or III settings. Although we were able to gain a representative sample from each setting, and used data saturation as our guide, the limited sample from the college setting may not completely reflect all athletic trainers' contextualization of the professional commitment. A more robust study can help fully conceptualize the idea of professional commitment, which is important as it has a direct relationship to retention in the workplace, a current concern within the profession.

The common core for our participants was the ability to provide the best possible healthcare to their student-athletes, which was done by being "current" and engaging in lifelong learning practices. Athletic trainers favor informal learning opportunities, but also require formal continuing education units to maintain certification as an athletic trainer; thus, supervisors and employers should encourage, support, and provide chances for professional development. This not only will be viewed as organizational support, a facet of professional commitment, but also other organizational tenets including job satisfaction and work-life balance.

Future studies can extrapolate on our findings by including a larger, more diverse sample. As the profession continues to grow and expand to other practice settings such as the military, industrial, and performing arts, it is important to uncover how professional commitment is defined and manifested as a means to stimulate retention. Furthermore, professional and organizational socialization can play a critical role in the development of professional commitment, as it is the process whereby the athletic trainer becomes familiar with the attitudes, values, and beliefs of the profession-founding aspects of professional commitment. Additionally, because our study only investigated how our participants defined professional commitment at one point in time, future research should consider a longitudinal approach.

\section{CONCLUSIONS}

Professional commitment has been defined variably by different scholars over the years, with most in agreement that there is a degree of emotional attachment and investment into the individual's profession. The most notable model, as to which many investigate professional commitment, is detailed by Meyer and Allen, which postulates three levels of commitment (affective, normative, and continuance). ${ }^{9}$ Coupling our findings with the existing literature in athletic training, it appears as though professional commitment can be loosely framed as a commitment that entails professional responsibility, continued and life-long learning, and at times, exceeding the expectations of the role to provide the best possible care for the student-athlete. Minimal differences can be detected between the levels within the collegiate setting, but there are notable differences in the definitions, likely due to the resources available within each.

\section{REFERENCES}

1. Profession. Merriam-webster dictionary. http://www.merriam-webster.com/dictionary/profession. Updated 2013. Accessed November 18, 2013.

2. Mazerolle SM, Bruening JE, Casa DJ, Burton LJ. Work-family conflict, part II: Job and life satisfaction in national collegiate athletic association division I-A certified athletic trainers. J Athl Train. 2008;43(5):513-22. [PMID: 18833314]

3. Mazerolle SM, Pitney WA, Casa DJ, Pagnotta KD. Assessing strategies to manage work and life balance of athletic trainers working in the national collegiate athletic association division I setting. J Athl Train. 2011;46(2):194-205. [PMID: 21391805]

4. Hendrix $\mathrm{AE}$, Acevedo EO, Hebert E. An examination of stress and burnout in certified athletic trainers at division I-a universities. J Athl Train. 2000;35(2):139-44. [PMID: 16558622]

5. Capel SA. Attrition of athletic trainers. Athletic Training Journal National Athletic Trainers' Association. 1990;25(1):34-9.

6. Terranova $A B$, Henning JM. National collegiate athletic association division and primary job title of athletic trainers and their job satisfaction or intention to leave athletic training. J Athl Train. 2011;46(3):312-8. [PMID: 21669102]

7. Aranya N, Pollock J, Amernic J. An examination of professional commitment in public accounting. Account Org Soc. 1981;6(4):271-28.

8. Winterstein AP. Organizational commitment among intercollegiate head athletic trainers: Examining our work environment. $J$ Athl Train. 1998;33(1):54-61. [PMID: 16558486] 
9. Meyer JP, Allen NJ. A three-component conceptualization of organizational commitment. Hum Resour Manage $R$. 1991;1:61-89.

10. Meyer JP, Allen NJ, Smith CA. Commitment to organizations and occupations: Extension and test of a three-component conceptualization. J App Psych. 1993;78:538-51.

11. Meyer JP. Commitment in the workplace: Theory, research, and application. In: Thousand Oaks, CA: Sage; 1997:23-38.

12. Nogueras DJ. Occupational commitment, education, and experience as a predictor of intent to leave the nursing profession. Nurs Econ. 2006;24(2):86-93. [PMID: 16676751]

13. Cunningham G,B., Sagas M, Ashley FB. Occupational commitment and intent to leave the coaching profession. Int Rev Soc Sport. 2001;36(2):131-48.

14. Aryee S, Chay YW, Chew J. An investigation of the predictions and outcomes of career commitment in three career stages. $J$ Vocat Behav. 1994;44:1-16.

15. Kahanov L, Eberman LE. Age, sex, and setting factors and labor force in athletic training. J Athl Train. 2011;46(4):424-30. [PMID: 21944075]

16. Lu KY, Chang LC, Wu HL. Relationships between professional commitment, job satisfaction, and work stress in public health nurses in Taiwan. J Pro Nurs. 2007;23(2):110-6. [PMID: 17383604]

17. Pitney WA. A qualitative examination of professional role commitment among athletic trainers working in the secondary school setting. J Athl Train. 2010;45(2):198-204. [PMID: 20210624]

18. Bruening JE, Dixon MA. Situating Work-Family negotiations within a life course perspective: Insights on the gendered experiences of NCAA division I head coaching mothers. Sex Roles. 2008;58(1-2):10-23.

19. Vandenberg RJ, Scarpello V. A longitudinal assessment of the determinant relationship between employee commitment to the occupation and the organization. J Org Behav. 1994;15:535-47.

20. Bagraim JJ. The dimensionality of professional commitment. J Indus Psych. 2003;29(2):6-9.

21. Denzin NK. In: Handbook of qualitative research. Thousand Oaks, CA: Sage; 1994:2-2.

22. Altheide $D$, Johnson J. Criteria for assessing interpretive validity in qualitative research. In: Denzin N, Lincoln $Y$, eds. Hanbook of qualitative research. Thousand Oaks, CA: Sage; 1994:485-99.

23. Pitney WA, Parker J. Qualitative research in physical activity and the health professions. Champaign, IL: Human Kinetics; 2009.

24. Meho LI. E-mail interviewing in qualitative research: A methodological discussion. J Am Soc Inf Sci Tec. 2006;57(10):128495.

25. Mazerolle SM, Eason CM, Pitney WA. Barriers to Maintaining Professional Commitment in Athletic Trainers in the Collegiate Setting. J Athl Train. Accepted May 26, 2014.

26. Eason CM, Mazerolle SM, Pitney WA. Facilitators of professional commitment for the athletic trainer in the college setting. J Athl Train. Accepted June 1, 2014.

27. Meyer JP, Allen NJ. A three-component conceptualization of organizational commitment: Some methodological considerations. Hum Resour Manage R. 2007;1:61-98.

28. Mensch J, Mitchell M. Choosing a career in athletic training: Exploring the perceptions of potential recruits. J Athl Train. 2008;43(1):70-9. [PMID: 18335016]

29. Mazerolle SM, Goodman A, Pitney WA. Factors influencing Retention of male athletic trainers in the NCAA Division I setting. IJATT. 2013;18(5).

30. Hoff TJ. Professional commitment among US physician executives in managed care. Soc Sci Med. 2000;50(10):1433-44. [PMID: 10741578]

31. Mazerolle SM, Pitney WA, Eason CM. Experiences of work-life balance for the athletic trainer employed in the non-division clinical setting. J Athl Train. Submitted November 7, 2013 In Review.

32. Mazerolle SM, Goodman A, Pitney WA. Achieving work-life balance in the NCAA division I setting part I: The role of the head athletic trainer. J Athl Train. In Press.

33. Mazerolle SM, Pitney WA, Goodman A. Strategies for athletic trainers to find a balanced lifestyle across clinical setting. IJATT. 2012;17(3):7-14.

34. Gould D, Fontenla M. Commitment to nursing: Results of a qualitative interview study. J Nurs Manag. 2006;14(3):213-21. 


\section{APPENDIX A}

Interview Guide: Professional Commitment

1. How would you describe the phrase "professional commitment"?

Probe: What does professional commitment mean to you?

2. What aspects of the profession do you have a passion for? That drives you?

3. Describe for me how you have maintained your level of commitment.

Probe: What keeps you motivated and enthusiastic in your work?

Probe: How have you dealt with the day-to-day-redundancies of your job?

Probe: What personal strategies do you utilize to sustain professional enthusiasm?

4. Describe for me how your work setting has influenced your professional commitment.

Probe (if negative influences)

How have you dealt with these influences?

Can you give a specific example?

Alternative: Have you ever had an experience where you felt as though your enthusiasm or commitment was compromised or not as it should be? If so, how did you respond?

5. How has your workplace environment influenced your professional commitment?

Probe: Co-workers play a factor in your commitment? Supervisors?

Probe: Has your responsibilities outside of the workplace influenced your professional commitment?

6. If you could change one thing about your work environment, to enhance your own professional commitment, what would that be?

Probe: Is this a realistic change for your work environment?

Probe: Is it plausible that this change could be made? What do you think it might take to implement this change?

7. What types of continuing education opportunities to you seek out (workshops, convention, etc.)?

8. What advice would you give a fellow athletic trainer or young professional regarding maintaining professional commitment? (How do you do it?) 